\title{
Preparation and biological activity of a paclitaxel-single-walled carbon nanotube complex
}

\author{
X.D. Fu ${ }^{1,2 *}$, Y.Y. Zhang ${ }^{3 *}$, X.J. Wang ${ }^{2}$, J.X. Shou ${ }^{2}$, Z.Z. Zhang ${ }^{4}$ and \\ L.J. Song ${ }^{1}$ \\ ${ }^{1}$ Department of Neurosurgery, \\ The First Affiliated Hospital of Zhengzhou University, Zhengzhou, China \\ ${ }^{2}$ Department of Neurosurgery, \\ The Fifth Affiliated Hospital of Zhengzhou University, Zhengzhou, China \\ ${ }^{3}$ Basic Medical Sciences College of Zhengzhou University, Zhengzhou, China \\ ${ }^{4}$ School of Pharmacy of Zhengzhou University, Zhengzhou, China \\ *These authors contributed equally to this study. \\ Corresponding author: L.J. Song \\ E-mail: xddoccn@126.com
}

Genet. Mol. Res. 13 (1): 1589-1603 (2014)

Received May 27, 2013

Accepted October 3, 2013

Published March 12, 2014

DOI http://dx.doi.org/10.4238/2014.March.12.11

\begin{abstract}
Single-walled carbon nanotubes (SWCNTs) have unique transmembrane abilities. The huge superficial area and abundance of $\pi$ electrons confer SWCNTs perfect absorptive capability toward proteins, nucleates, and many drugs. These characteristics make SWCNTs a new and efficient drug carrier. The purpose of this study was to disperse SWCNTs in water and have paclitaxel absorbed onto them in order to construct an asparagine-glycine-arginine (NGR)-SWCNT-Paclitaxel complex as a targeting nanoparticle system. The NGR-SWCNTPaclitaxel complex was systematically studied, and analytical methods, including spectrophotometry for SWCNTs and high-performance liquid chromatography for paclitaxel, were employed. The preparation and the prescription of the NGR-SWCNT-Paclitaxel complex lyophilized
\end{abstract}


powder were investigated. MCF-7 cancer cells, Sprague-Dawley rats, and S180 tumor-bearing mice were used as experimental subjects to evaluate the in vitro and in vivo activity of NGR-SWCNT-Paclitaxel complex dispersion. The complex dispersion showed obvious inhibition activity against MCF-7 cancer cells. Within $1 \mathrm{~h}$, the NGRSWCNT-Paclitaxel complex could be transferred to cells, and sustained the release of drugs. In addition, the tumor and liver targeting and improved therapeutic effects of the NGR-SWCNT-Paclitaxel complex were confirmed.

Key word: Paclitaxel; SWCNT; NGR; Antitumor; Nano-preparation

\section{INTRODUCTION}

The incidence of cancer is currently growing every year. In China, the National Cancer Registration Center recently released the "2012 China Tumor Registries Annual Report", which showed that in the last few decades, increasingly younger patients are suffering from cancer, and that the morbidity and mortality rates have increased. There are 3.12 million new cancer cases diagnosed every year, which means that six people are diagnosed with cancer every minute. Paclitaxel, as an important anticancer drug, is a secondary metabolite that was first isolated from plants of the genus Taxus by Wall et al. in 1963. As a natural tetracyclic diterpene compound, the drug mechanism is based on its microtubule functions. Paclitaxel promotes microtubule protein polymerization, inhibiting the composition of cell inner frames and interference of cell mitosis; therefore, it has been widely used in clinics for treating breast cancer, ovarian cancer, and non-small-cell lung cancer. However, because paclitaxel is not a targeting medicine and is not completely water-soluble, it can result in various side effects of chemotherapy including myelosuppression, neurovirulence, cardiovascular toxicity, hepatotoxicity, anaphylaxis, etc. Therefore, an efficient drug carrier for paclitaxel to specifically target the cancer is urgently needed.

Carbon nanotubes (CNTs) represent a new drug delivery method with unique physical, chemical, and biological characteristics (Xiao et al., 2009; Majumder et al., 2010; Adolph et al., 2012; Matthews et al., 2013). There are 2 main kinds of CNTs: single-wall CNTs (SWCNTs) and multi-wall CNTs. Studies have found that CNTs have a unique feature defined as a transmembrane, which enables them to pass through various cell membranes passively (Andersen et al., 2013). However, CNTs are highly hydrophobic, are insoluble in both water and organic solvents, and their biocompatibility is very poor. Therefore, unfunctionalized CNTs are toxic to organisms (Sinnott, 2002; Kam et al., 2006). However, based on the transmembrane of CNTs, researchers have found that those properly functionalized could transport biomolecules or drugs into cells without toxicity (Sundararajan and Ghosh, 2011; Adolph et al., 2012; Bearden and Zhang, 2013). CNTs are composed of carbon atoms with SP2 hybrid orbitals, and contain high amounts of highly delocalized $\pi$ electrons, which facilitate the combination of CNTs with compounds containing $\pi$ electrons, such as polypeptides, proteins, phospholipids, etc.

In our study, phenylalanine was used to functionalize SWCNTs to improve their water-solubility. Since the asparagine-glycine-arginine (NGR) complex can connect to amino- 
peptidase-N $\left(\mathrm{CD}_{13}\right)$, which is only expressed on tumor cells, NGR was employed to modify SWCNTs for targeting the cancer. After SWCNTs were functionalized and modified, paclitaxel was dispersed and adsorbed on the SWCNTs to construct the NGR-SWCNT-Paclitaxel complex.

\section{MATERIAL AND METHODS}

\section{SWCNT-Paclitaxel complex}

There are currently no mature preparation methods for SWCNT complexes (Maehana et al., 2010; Duque et al., 2013). In this study, three different methods were tested, including the precipitation method (PM), the adsorption method (AM), and the grinding method (GM) (Ohta et al., 2010). For the PM, recipe quantity paclitaxel was dissolved in alcohol, to which recipe quantity SWCNTs was added. Ultrapure water was dropped into the system in the ultrasonic environment, and the SWCNT-Paclitaxel complex was obtained by centrifugation. The complex was mixed with a surfactant solution of recipe quantity, and after ultrasonic disposal, the SWCNT-Paclitaxel complex (SP complex) dispersion solution could be obtained when dissociative paclitaxel and SWCNTs were removed by centrifugation. For the AM method, SWCNTs were added to the surfactant solution and were dispersed by using an ultrasonic probe. Undispersed SWCNTs were removed by centrifugation, and then recipe quantity paclitaxel was added to the dispersion and ultrasonic-dissolved. SWCNT-Paclitaxel complex dispersion could be obtained after the removal of dissociative paclitaxel. In the GM, SWCNTs, recipe quantity paclitaxel, and ethyl alcohol were placed into agate mortar. The system was ground for $2 \mathrm{~h}$ and the alcohol was evaporated by vacuumization. The SWCNT-Paclitaxel complex was mixed with surfactant solution, ultrasonic disposed, and centrifuged, and then the SWCNT-Paclitaxel complex dispersion was determined.

\section{SP complex process}

In this study, the loading rate (LR) and the encapsulation efficiency (EN) were regarded as the major indicators for the investigation.

The LR and EN were calculated according to the formula:

$$
\begin{gathered}
\mathrm{LR}=(\text { total concentration of paclitaxel }- \text { concentration of dissociated paclitaxel }) / \\
\text { concentration of SWCNTs }
\end{gathered}
$$

To compare the LR and EN of the three preparation methods, $10.0 \mathrm{mg}$ SWCNTs, 0.5 $\mathrm{mL} 40 \mathrm{mg} / \mathrm{mL}$ paclitaxel ethyl alcohol solution, and $5 \mathrm{~mL} 10 \mathrm{mg} / \mathrm{mL}$ Poloxamer 188 solution were mixed, and the SP complexes were prepared by PM, AM, and GM, respectively.

To determine the influence of SWCNTs and the paclitaxel reactant ratio on LR, four exact doses of $10.0 \mathrm{mg}$ SWCNTs were added to $10,20,40$, and $80 \mathrm{mg} / \mathrm{mL}$ paclitaxel alcohol solution, respectively, which resulted in SWCNT:paclitaxel at mass ratios of 2:1, 1:1, 1:2, and 1:4. Then, the SP complexes were prepared by using the three methods (PM, AM, and GM). 
The LRs and ENs of the different methods were then compared.

\section{Construction and evaluation of NGR-SWCNT-Paclitaxel complex}

In the 1,2-distearoyl-sn-glycero-3-phosphoethanolamine-N (DSPE-PEG)-Maleimide molecule, maleimide can react with sulfhydryl at room temperature. Therefore, DSPE-PEGMaleimide could bond to NGR by cysteine, and the DSPE group could be absorbed onto SWCNTs, as shown in Figure 1.

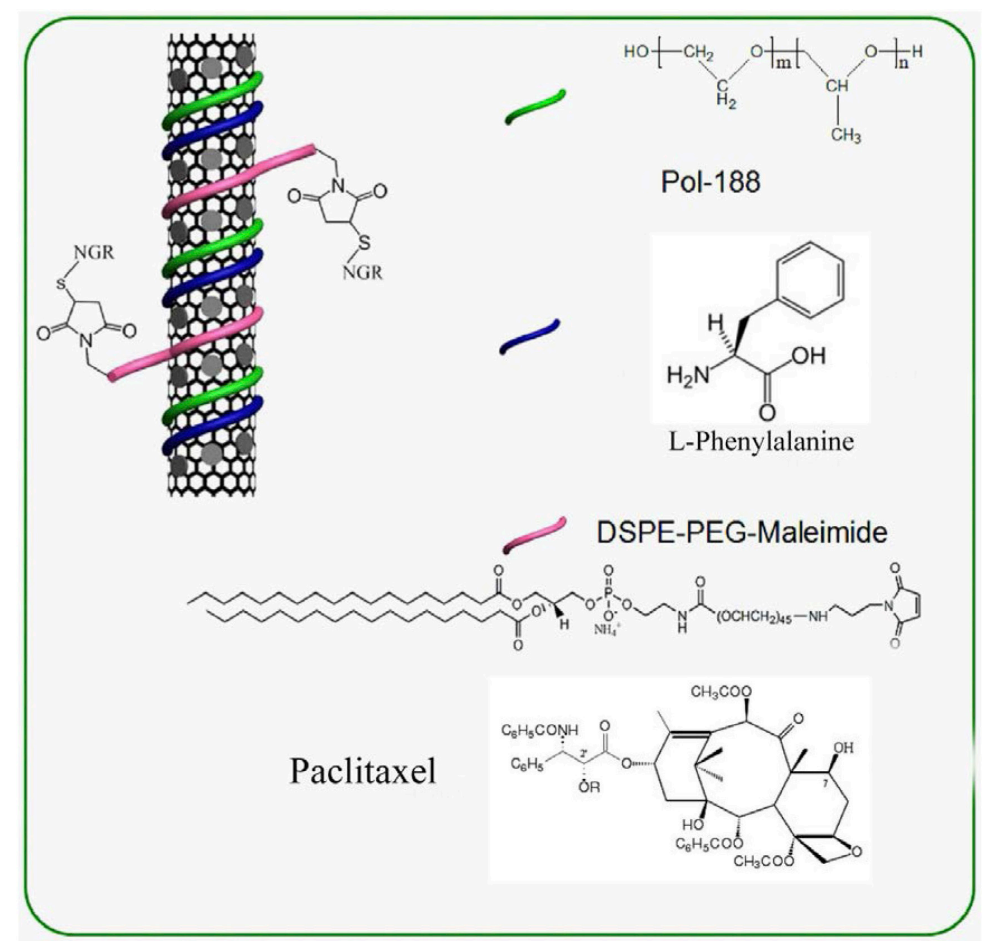

Figure 1. Diagram of NGR-SWCNT-Paclitaxel.

Next, $0.2 \mathrm{mg}$ DSPE-PEG2000-Maleimide was added to $2 \mathrm{~mL}$ SP complex dispersion, and after 20-min ultrasonic treatment, poloxamer188 was added to adjust the concentration to $2.0 \mathrm{mg} / \mathrm{mL}$. Ultrasonic treatment was performed again, and the system was filtrated through a $100-\mu \mathrm{m}$ membrane. The DPM-modified SP complex was obtained after redispersion with ultrapure water. The NGR polypeptide solution was placed in the system at a 15:1 NGR:DPM ratio, and was reacted overnight in the dark. Once the unreacted NGR polypeptide was filtered through the membrane, the NGR-SWCNT-Paclitaxel complex was constructed.

To evaluate the NGR-SWCNT-Paclitaxel complex, the particle size distribution (PSD) and the zeta potential were inspected using the Nano-ZS90 Laser diffraction particle size analyzer (LDSA) system. Scanning electron microscopy (SEM), transmission electron microscopy (TEM), and atomic force microscopy (AFM) were also employed to investigate the NGR-SWCNT-Paclitaxel complex system. 
Through a series of experiments, the optimal condition of the lyophilized preparation was determined. The NGR-SWCNT-Paclitaxel complex was placed in a 2-mL EP tube, to which a $5 \%$ sucrose:lactose mixture (4:1) was added. The system was completely dissolved and mixed in a constant temperature oscillator at $37^{\circ} \mathrm{C}$ for $30 \mathrm{~min}$. After pre-freezing for $6 \mathrm{~h}$ at $-40^{\circ} \mathrm{C}$, lyophilized powder could be obtained through $24 \mathrm{~h}$ of freeze-drying in a lyophilizer.

\section{Paclitaxel delivery system}

MCF-7 cells were cultured in an incubator at $5 \% \mathrm{CO}_{2}$ in RPMI1640 medium with $10 \%$ fetal bovine serum and $100 \mathrm{U} / \mathrm{mL}$ penicillin/streptomycin at $37^{\circ} \mathrm{C}$ for one-generation passage over 2-3 days.

Fluorescein isothiocyanate (FITC) has multiple aromatic rings, and could be absorbed on the surface of CNTs by $\pi$ - $\pi$ stacking interactions. One milliliter $1 \mathrm{mg} / \mathrm{mL}$ FITC dimethyl sulfoxide solution was added to $5 \mathrm{~mL}$ NGR-SWCNT-Paclitaxel dispersion solution. After ultrasonic dissolution, $24 \mathrm{~h}$ standing, and purification with dextrangel, the FITC-labeled NGRSWCNT-Paclitaxel complex was obtained, which could be measured using fluorescence spectrophometry.

The experiment evaluated three treatment groups, the NGR-SWCNT-Paclitaxel-FITC group (NSPF group), the SWCNTs-Paclitaxel-FITC group (SPF group), and the FITC group (F group), and a control group. The concentration of FITC was the same in every group, and $1 \mu \mathrm{g} / \mathrm{mL}$ paclitaxel was used in all pharmaceutical groups.

MCF-7 cells were placed on 6-well culture plates at a density of $0.8-1.0 \times 10^{6}$ cells/ well and were cultured for $24 \mathrm{~h}$. Then, the culture medium was removed and cells were washed with phosphate-buffered saline 3 times, and cultured in medicated media. Three experimental wells were respectively cultured for 1, 2, and $4 \mathrm{~h}$, and the cells were washed and fixed in $75 \%$ alcohol. Subsequently, cells were observed under a fluorescence microscope, and intakes were recorded. The SPF group, F group, and control group were all treated with the same procedure as described above.

The 3,[4,5-dimethylthiazol-2-yl]-2,5-diphenyltetrazolium bromide (MTT) assay was employed to detect the survival of cells, and the living cell amount was determined by using an enzyme-linked immunosorbent assay (ELISA) at a 570-nm wavelength. The inhibition rate was calculated based on subtracting the optical density of the blank group from those of the experimental and control groups.

Different cancer cell types, including EC9706, SPC-A-1, SMMC-7721, MCF-7, and PC-3 cells, were treated and detected by using the MTT assay. The inhibition activities of 8.0 $\mu \mathrm{g} / \mathrm{mL}$ NGR-SWCNT-Paclitaxel complex against different cancer cells were evaluated and compared.

\section{NGR-SWCNT-Paclitaxel complex}

Mouse180 ascitic tumor cells were diluted in normal saline at a $3: 1$ ratio, $0.3 \mathrm{~mL}$ cell suspension was injected into every mouse, and the mice were maintained for a further 7 days following injection. Mouse ascites were extracted and diluted into cell suspensions at a $2 \times 10^{6} / \mathrm{mL}$ ascitic tumor cell density. The suspension was subcutaneously inoculated to the mice's right forelimbs. Seven days later, mice with tumors $\geq 100 \mathrm{~mm}^{3}$ were selected for use as tumor-bearing models. 
The paclitaxel plasma samples were prepared by adding $200 \mu \mathrm{L}$ paclitaxel standard solution to $2 \mathrm{~mL}$ methyl tertiary butyl ether (MTBE). After oscillation and centrifugation, the upper clear liquid was removed and dried in nitrogen at $40^{\circ} \mathrm{C}$.

Blank plasma samples were prepared by adding $200 \mu \mathrm{L}$ heparinized plasma to $2 \mathrm{~mL}$ MTBE. After oscillation and centrifugation, the upper clear liquid was removed and dried in nitrogen at $40^{\circ} \mathrm{C}$.

Paclitaxel contents were evaluated in tissue samples from the brain, liver, spleen, kidney, and tumors of rats. Tissues were removed and weighed and a 3-time weight homogenate (1:1 normal saline:acetonitrile) was added to prepare the tissue homogenates. A $10-\mu \mathrm{L}$ aliquot paclitaxel standard solution and $2 \mathrm{~mL}$ MTBE were added to $200 \mu \mathrm{L}$ tissue homogenate. After oscillation and centrifugation, the upper clear liquid was removed and dried in nitrogen at $40^{\circ} \mathrm{C}$.

The blank tissue samples were prepared by adding $200 \mu \mathrm{L}$ tissue homogenate to $2 \mathrm{~mL}$ MTBE. The upper clear liquid was removed after oscillation and centrifugation, and dried in nitrogen at $40^{\circ} \mathrm{C}$.

Samples were redissolved in $100 \mu \mathrm{L}$ mobile phase, and then oscillated and centrifuged before liquid chromatography (LC) analysis. The LC conditions were:

Eclipse XDB-C18 chromatographic column ( $150 \times 4.6 \mathrm{~mm}, 5 \mu \mathrm{m}), 227 \mathrm{~nm}$ detection wavelength, $60: 40$ mobile phase:acetonitrile, $1.0 \mathrm{~mL} / \mathrm{min}$ flow velocity, room temperature column temperature, and $20 \mu \mathrm{L}$ sample concentration.

The paclitaxel standard substance was added to the tissue homogenate and prepared into $1,2,4,8,16,24$, and $40 \mu \mathrm{g} / \mathrm{mL}$ standard samples, which were inspected by $\mathrm{LC}$, and a regression equation was established according to the linear regression of the peak area (A) vs concentration $(\mathrm{C})$.

Blank rat plasma was added to the paclitaxel standard solution and prepared into 30 , 15 , and $3 \mu \mathrm{g} / \mathrm{mL}$ plasma samples. Samples were inspected using LC, and the average recovery rate was calculated. The three-concentration samples were injected every hour 5 consecutive times to achieve intra-day precision.

The tumor-bearing mice were separated into 3 groups, with 6 animals per group. Either $20.0 \mathrm{mg} / \mathrm{kg}$ NGR-SWCNT-Paclitaxel complex dispersion, SP complex, or paclitaxel control solution were respectively injected through the caudal vein into tumor-bearing mice. The three groups of mice were sacrificed $30 \mathrm{~min}, 1 \mathrm{~h}$, and $3 \mathrm{~h}$ after injection. The heart, liver, spleen, lung, kidney, brain, and tumor tissues were disposed of and inspected by HPLC following the same procedure described above.

Thirty S180 tumor-bearing male Kunming mice (mean weight $20 \pm 2 \mathrm{~g}$ ) were separated into 5 groups: the control (normal saline) group (C group), the NGR-SWCNTs group (NS group), the paclitaxel group (P group), the SWCNTs-Paclitaxel group (SP group), and the NGR-SWCNT-Paclitaxel group (NSP group). Mice in each group were administered with each treatment by injection through the caudal vein. The P, SP, and NSP groups received 20 $\mathrm{mg} / \mathrm{kg}$ paclitaxel, and the NS and NSP groups received $20 \mathrm{mg} / \mathrm{kg}$ SWCNTs. Mouse models were treated every 2 days and were consecutively injected a total of 7 times. Each mouse was observed and tumors were measured with Vernier calipers. The tumor volume was calculated using the formula:

$$
\mathrm{V}=\mathrm{A} \times \mathrm{B}^{2} / 2
$$

where $\mathrm{A}=$ tumor of long diameter and $\mathrm{B}=$ tumor of short diameter. 
Mice were sacrificed when the treatment was finished. The heart, liver, spleen, lung, kidney, and tumor tissues were made into hematoxylin and eosin (HE)-stained paraffin sections. The histomorphologies of the five groups were observed under microscope.

\section{RESULTS AND DISCUSSION}

\section{Determination of SP complex preparation}

The NGR polypeptide (A), the NGR and SWCNTs mixture (B), and the NGRSWCNT-Paclitaxel complex (C) were analyzed by thin layer chromatography. Both A and B showed NGR fluorescence spots, while C did not, which indicated that NGR had completely combined with the SWCNTs.

The mechanical mixture of paclitaxel with excipients and the NGR-SWCNT-Paclitaxel complex were analyzed by differential scanning calorimetry (Shanthi et al., 2013). The paclitaxel peak disappeared after it was absorbed by the SWCNTs. This means that paclitaxel did not exist as a crystal, but was instead loaded on the SWCNTs. The differential scanning calorimetry results are shown in Figure 2.
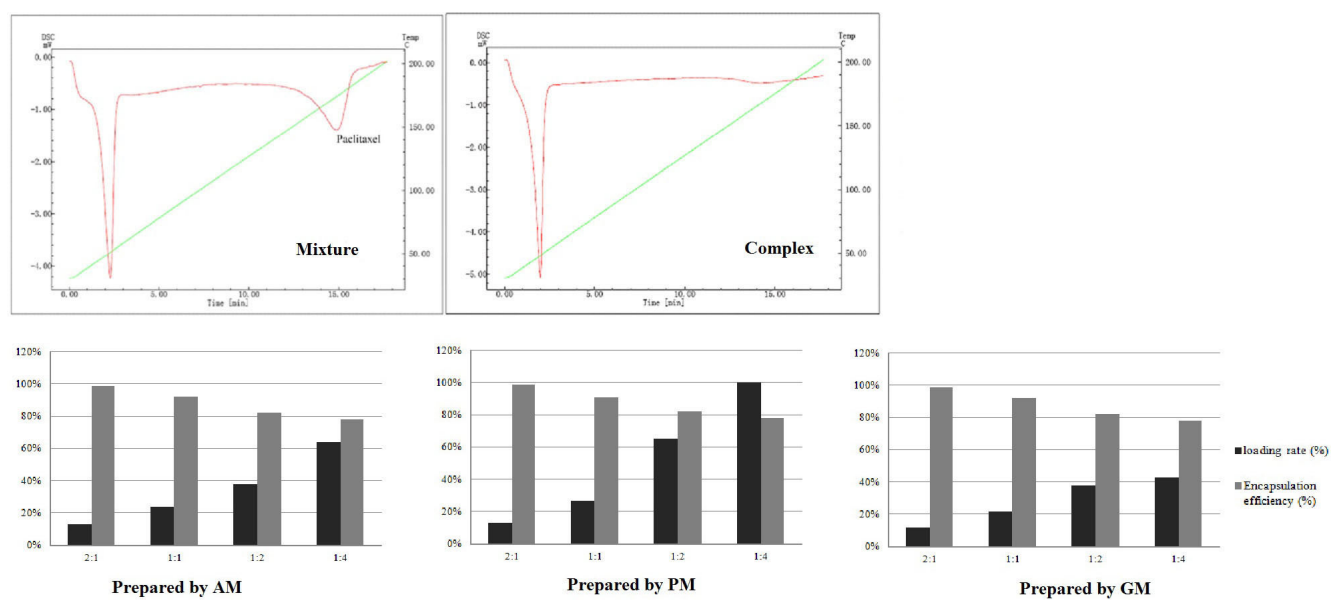

Figure 2. Loading rate of different methods and encapsulation efficiency of different reactant ratios. AM= absorption method; $\mathrm{PM}=$ precipitation method; $\mathrm{GM}=$ grinding method.

Comparison among methods indicated that the PM yielded the best paclitaxel LR (Figure 2).

Using the PM, the LR of SWCNTs increased with increasing paclitaxel concentration; however, the loss rate of paclitaxel increased at the same time. Therefore, the optimal reactant ratio for the PM was 1:2. Furthermore, the LR of the PM was much larger than those of the $\mathrm{AM}$ and GM were, as shown in Figure 2.

\section{Pharmaceutical evaluation}

The NGR-SWCNT-Paclitaxel complex dispersion was inspected in parallel three 
times, and PSD and zeta potential agents are shown in Table 1.

Table 1. Particle size distribution (PSD) and zeta potential agents of the NGR-SWCNT-Paclitaxel complex.

\begin{tabular}{lccc}
\hline Case & Size $(\mathrm{nm})$ & PSD & Zeta (mv) \\
\hline Sample 1 & $182.8 \pm 2.8$ & $0.200 \pm 0.013$ & $-22.06 \pm 0.71$ \\
Sample 2 & $180.7 \pm 2.7$ & $0.198 \pm 0.026$ & $-24.12 \pm 0.75$ \\
Sample 3 & $179.5 \pm 2.3$ & $0.201 \pm 0.025$ & $-23.88 \pm 0.64$ \\
\hline
\end{tabular}

The PSD data showed that the diameter of the nanopowder was $180 \mathrm{~nm}$ (Figure 3). TEM indicated that the SWCNTs were of filiform morphology, and were absorbed with the particles, which were paclitaxel microcrystals and surfactants, as shown in Figure 3. The AFM results revealed that the particle size was quite uniform, and the SWCNT appeared spiculate based on the tubular structure, as shown in Figure 3.
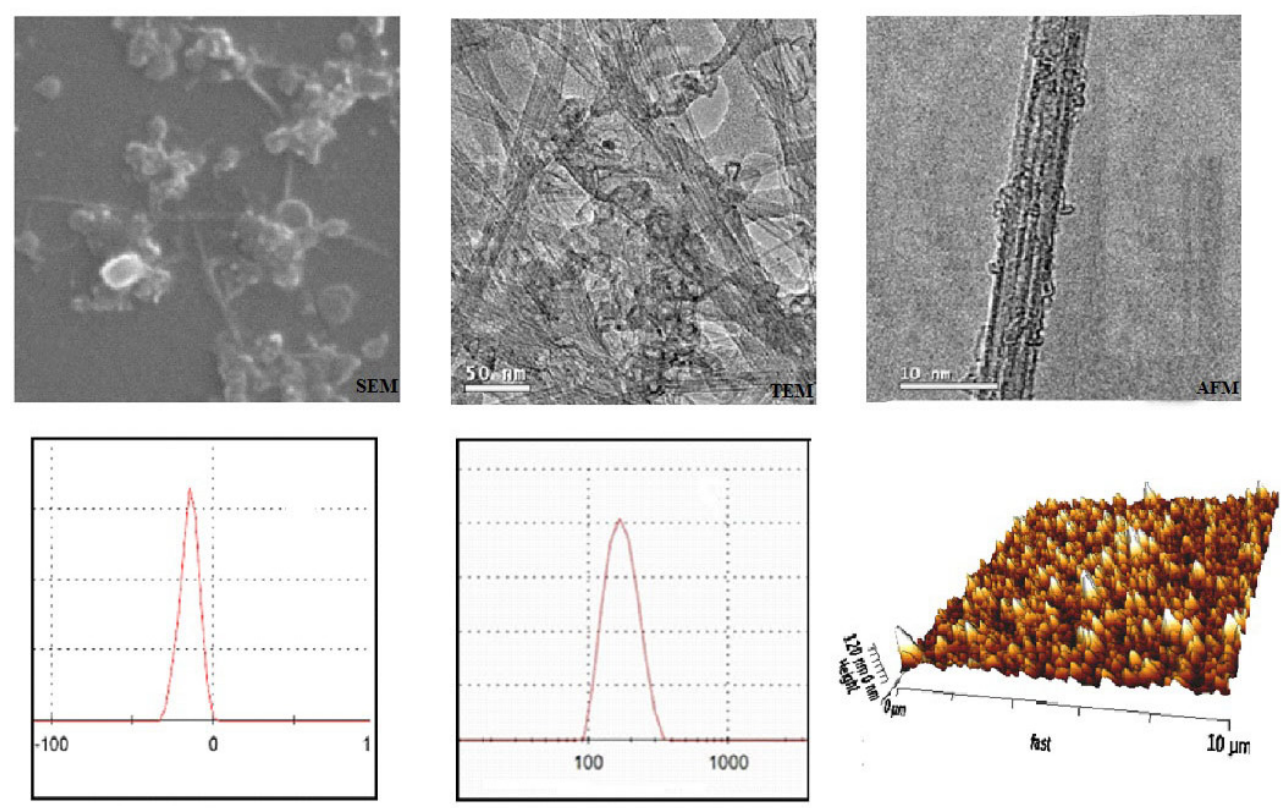

Zeta Potenial (mV)

Particle Size Distribution (nm)

Figure 3. SEM/TEM/AFM and zeta potential/particle size distribution of the NGR-SWCNT-Paclitaxel complex.

The LRs and ENs were determined and are listed in Table 2.

Table 2. Loading rate and encapsulation efficiency of the NGR-SWCNT-Paclitaxel complex.

\begin{tabular}{lccccc}
\hline Case & \multicolumn{3}{c}{ Concentration $(\mu \mathrm{g} / \mathrm{mL})$} & Loading rate (\%) & Encapsulation efficiency (\%) \\
\cline { 2 - 4 } & SWCNTs & Paclitaxel & Free Paclitaxel & & 98.31 \\
\hline 1 & 896.3 & 1452.3 & 24.5 & 159.3 & 98.60 \\
3 & 895.4 & 1478.2 & 21.6 & 164.7 & 98.32 \\
\hline
\end{tabular}


Through a series of experiments, it was discovered that when the pre-freezing temperature was lower than $-40^{\circ} \mathrm{C}$, the potential and PSD would remain after the lyophilized powder was redissolved. This demonstrated that the NGR-SWCNT-Paclitaxel complex had excellent stability.

\section{In vitro activity}

In order to verify that the complex could be transferred to cells, the three treatment groups (NSPF, SPF, and F), along with the control group, were inspected at 1, 2, and $4 \mathrm{~h}$ for changes in drug concentration. Figure 4 shows that the NSPF and SPF groups had more rapid uptake and a higher paclitaxel concentration in cells.
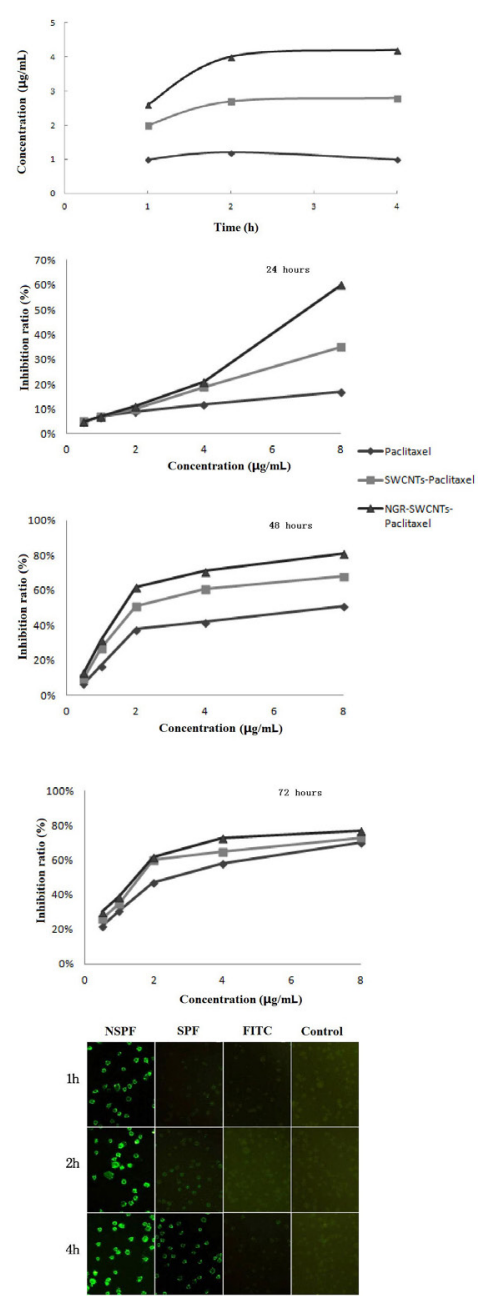

Figure 4. MCF-7 cell uptake of drug delivery system, the inhibition of NSPF/SPF/paclitaxel on MCF-7 cells, and the fluorescence microscopic images. FITC $=$ fluorescein isothiocyanate group; NSPF $=$ NGR-SWCNT-PaclitaxelFITC group; SPF = SWCNT-Paclitaxel-FITC group. 
Fluorescence microscope observations were used to examine the cellular uptake of the NGR-SWCNT-Paclitaxel-FITC complex, and results are shown in Figure 4. Compared with the control group, the NSPF group showed strong fluorescence, and the fluorescence intensity increased over time. This indicated that MCF-7 cells could efficiently phagocytize the NGR-SWCNT-Paclitaxel complex. The SPF group was also absorbed by MCF-7 cells, but the fluorescence signal was weak and required a relatively long time. The F group showed no fluorescence.

Inhibition activity was investigated with MCF- 7 cells at 24,48 , and $72 \mathrm{~h}$. There was no distinct difference between the three experimental groups at low concentrations; however, differences in inhibition activity became increasingly apparent with increasing concentration. As shown in Figure 5, the NSPF and SPF groups had much better inhibition activities than did the paclitaxel group. Over time, all three groups showed an obvious increase of inhibition, and the NSPF group showed the best inhibition efficiency. This demonstrated that the NGR-SWCNT-Paclitaxel complex could help the transference of paclitaxel into cells, and that in particles, the NGR polypeptide could accelerate this process and improve the inhibition efficiency (Luan et al., 2012; Luo et al., 2013; Matthews et al., 2013; Zucali et al., 2013).
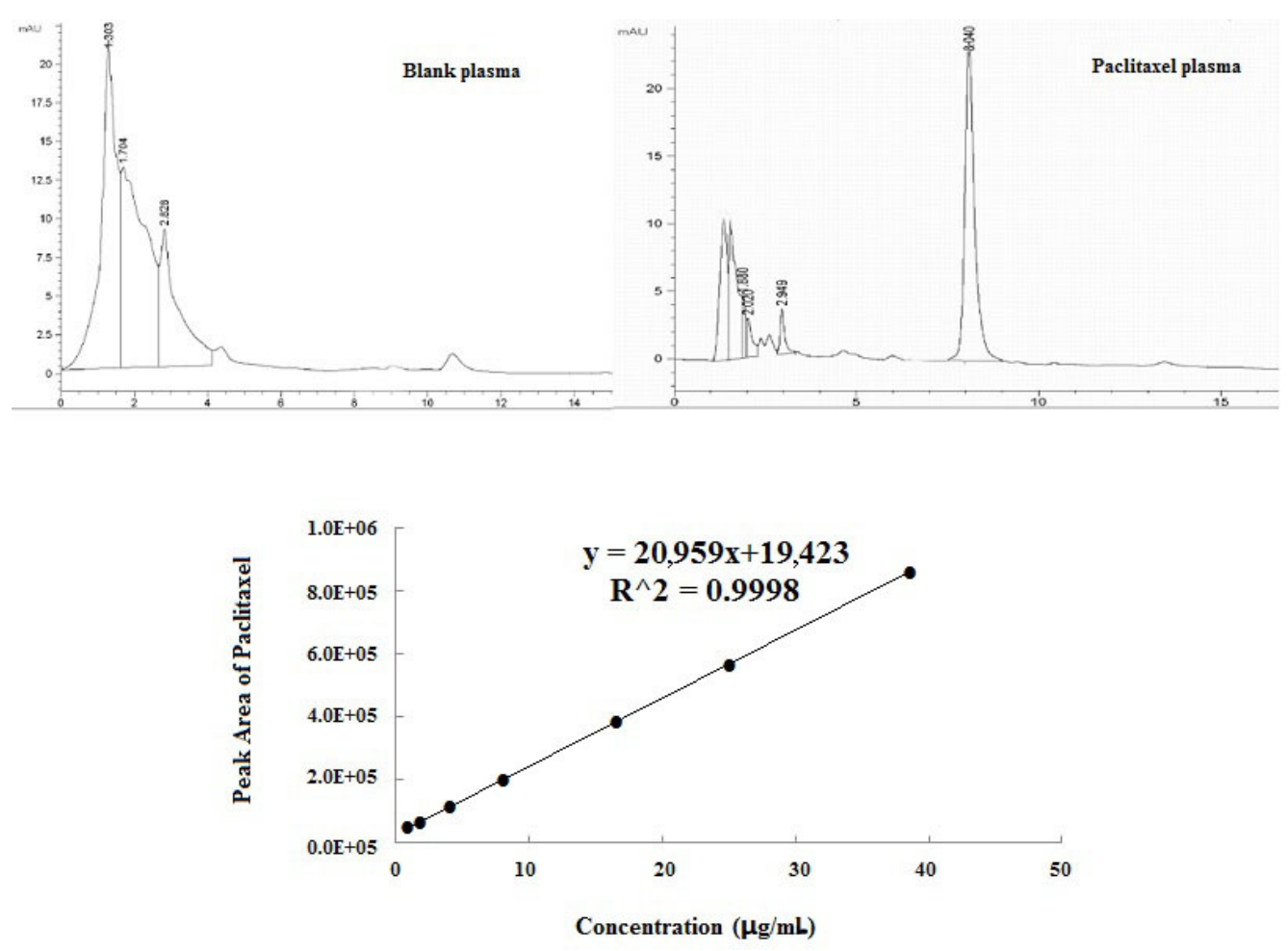

Figure 5. Typical chromatograms of Paclitaxel and the standard curve.

\section{Detection of plasma sample}

The LC results indicated that endogenous substances had little effect on paclitaxel, 
and that a proper separation degree was achieved. The retention time of paclitaxel was 8.040 min, as shown in Figure 5.

The plasma standard solutions were inspected, and the standard curve could be drawn on the linear regression of peak areas $v s$ concentration. The regression equation was determined as: $y=20,959 x+19,423$, which demonstrated a good linear relationship (Figure 5).

\section{NGR-SWCNT-Paclitaxel complex}

The results of the paclitaxel recovery assay are shown in Table 3, and the precision data are shown in Table 4 . The recovery rates at different concentrations were all above $85 \%$, and the standard deviations were all lower than $15 \%$. The inter-batch and intra-batch precision $v s$ standard deviations were all lower than $10 \%$. These results indicated that the experiments met the methodology requirement of biological sample detection.

Table 3. Recovery of paclitaxel in plasma.
\begin{tabular}{lcccc}
\hline Concentration $(\mu \mathrm{g} / \mathrm{mL})$ & Extraction recovery $(\%)$ & \multicolumn{2}{c}{ Method recovery $(\%)$} \\
\cline { 2 - 3 } & Mean \pm SD $(\%)$ & RSD $(\%)$ & Mean \pm SD $(\%)$ & RSD $(\%)$ \\
\hline 3.0 & $95.42 \pm 5.33$ & 5.81 & $102.65 \pm 4.32$ & 4.52 \\
15.0 & $92.28 \pm 4.89$ & 5.54 & $103.73 \pm 5.81$ & 5.75 \\
30.0 & $89.97 \pm 4.85$ & 5.33 & $95.67 \pm 3.76$ & 3.92 \\
\hline
\end{tabular}

Table 4. Inter-batch and intra-batch precision of paclitaxel in plasma.

\begin{tabular}{lcccc}
\hline Concentration $(\mu \mathrm{g} / \mathrm{mL})$ & \multicolumn{2}{c}{ Intra-batch } & \multicolumn{2}{c}{ Inter-batch } \\
\cline { 2 - 5 } & Mean $\pm \mathrm{SD}(\mu \mathrm{g} / \mathrm{mL})$ & $\mathrm{RSD}(\%)$ & Mean $\pm \mathrm{SD}(\mu \mathrm{g} / \mathrm{mL})$ & $\mathrm{RSD}(\%)$ \\
\hline 3.0 & $3.01 \pm 0.152$ & 5.66 & $3.14 \pm 0.187$ & 6.65 \\
15.0 & $15.12 \pm 0.510$ & 3.77 & $15.11 \pm 0.534$ & 3.95 \\
30.0 & $30.45 \pm 0.561$ & 2.05 & $30.14 \pm 0.631$ & 2.34 \\
\hline
\end{tabular}

The concentrations of the complex were inspected in each organ by using the same assay as "Paclitaxel contents were evaluated in tissue samples" above, and results are shown in Figure 6.

\section{Analysis of tissue distribution}

In this study, the overall targeting efficiency (TE), targeting index (TI), and relative overall targeting efficiency (RTE) were calculated to evaluate the in vivo targeting of the NGR-SWCNTPaclitaxel complex (Gao et al., 2013; Germano et al., 2013; Shahin et al., 2013). The TE indicates the percentage of tissue distribution, the TI indicates the variation in the medicine concentration between the experimental and control group tissues, and the RTE represents the relativity value of the variation. Each of these variables were calculated using the following formulae:

$$
\boldsymbol{E}=\frac{\left(A U C_{0 \rightarrow 3 h}\right) i}{\sum_{i=1}^{n}\left(A U C_{0 \rightarrow 3 h}\right)} \times 100 \%
$$




$$
\begin{aligned}
& \boldsymbol{T}=\frac{\left(A U C_{0 \rightarrow 3 h}\right) E}{\left(A U C_{0 \rightarrow 3 h}\right) C} \times 100 \% \\
& R T E=\frac{\boldsymbol{E}_{C}-\boldsymbol{E}_{E}}{\boldsymbol{E}_{C}} \times 100 \%
\end{aligned}
$$

where $i=$ each tissue, $\mathrm{E}=$ experimental group, and $\mathrm{C}=$ control group, $\mathrm{AUC}=$ area under the curve. The $\mathrm{AUC}_{0 \rightarrow 3 \mathrm{~h}}$ was calculated with the trapezoid method.

As shown in Tables 5 to 7, the NSP group had distinctive tumor targeting efficiency. The SP group had perfect targeting to twhe liver. In the brain, the paclitaxel concentration was not detectable. There were no obvious differences between the heart, spleen, and kidney. These results demonstrated that the NGR-SWCNT-Paclitaxel complex had specific targeting toward tumors and the liver.

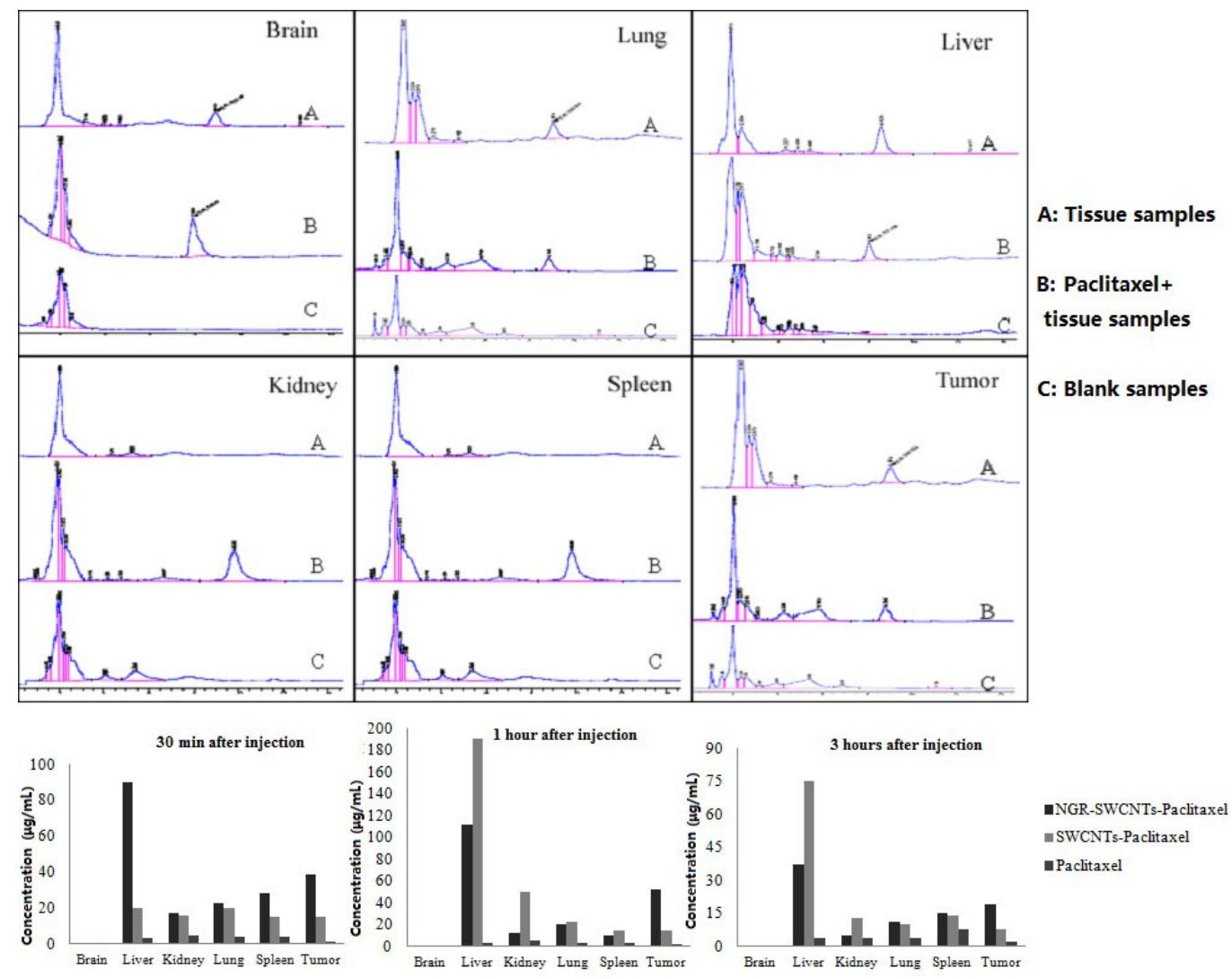

Figure 6. HPLC spectrum of tissue samples and the paclitaxel concentrations in different times. 


\begin{tabular}{lccc} 
Table 5. $\mathrm{AUC}_{0 \rightarrow 3 \mathrm{~h}}$ of tissue in mice after intravenous injection. \\
\hline Sample & Poclitaxel AUC & SWCNTs-Paclitaxel AUC & SWCNTs-Paclitaxel-NGR AUC \\
\hline Brain & - & - & - \\
Liver & 2.367 & 396.313 & 202.266 \\
Spleen & 16.268 & 51.630 & 20.562 \\
Lung & 13.611 & 40.466 & 36.181 \\
Kidney & 8.210 & 88.148 & 33.176 \\
Tumor & 1.999 & 15.911 & 53.078 \\
\hline
\end{tabular}

$\mathrm{AUC}=$ are under the curve.

Table 6. Targeting parameters of tissue in mice after intravenous injection.

\begin{tabular}{lccrr}
\hline Sample & \multicolumn{2}{c}{ TE (\%) } & TI (\%) \\
\cline { 2 - 4 } & SWCNTs-Paclitaxel & Docetaxel & \\
\hline Brain & 0 & 0 & - & RTE (\%) \\
Liver & 84.370 & 6.919 & 20760.2 & - \\
Spleen & 10.986 & 47.517 & 393.6 & -1123.1 \\
Lung & 8.618 & 39.754 & 368.6 & 95.3 \\
Kidney & 18.761 & 23.982 & 1331.3 & 97.1 \\
Tumor & 11.252 & 5.840 & 1366.7 & 27.0 \\
\hline
\end{tabular}

$\mathrm{TE}=$ targeting efficiency; $\mathrm{TI}=$ targeting index; $\mathrm{RTE}=$ overall targeting efficiency.

Table 7. Targeting parameters of tissue in mice after intravenous injection.
\begin{tabular}{lccrr}
\hline Sample & TE (\%) & TI (\%) & \\
\cline { 2 - 5 } & NGR-SWCNT-Paclitaxel & Docetaxel & - & RTE (\%) \\
\hline Brain & 0 & 0 & 10595.4 & -1101.8 \\
Liver & 79.558 & 6.919 & 156.7 & 102.9 \\
Spleen & 8.085 & 37.517 & 329.6 & 59.6 \\
Lung & 14.235 & 23.754 & 501.1 & 56.5 \\
Kidney & 13.045 & 5.840 & 6431.6 & -408.7 \\
Tumor & 49.077 & & \\
\hline
\end{tabular}

$\mathrm{TE}=$ targeting efficiency; $\mathrm{TI}=$ targeting index; $\mathrm{RTE}=$ overall targeting efficiency.

\section{Antitumor activity}

The influence on tumor volume was observed and results are shown in Figure 7. The tumor volumes of the P, SP, and NSP groups were all much smaller than that of the control group. Furthermore, the NSP group showed a better curative effect compared to the P and SP groups.

Furthermore, there were no obvious differences among the major organs investigated (Figure 7), which suggests that this therapeutic schedule would not lead to any viscera toxicity. The tumor tissues of the control and NS groups were clearly dyed and the cell boundaries were integrated. However, for the P, SP, and NSP groups, the tumor tissues had cells broken at different levels. Among these groups, the NSP group showed the most obvious cell breakage, and several of the cells were not dyed. 


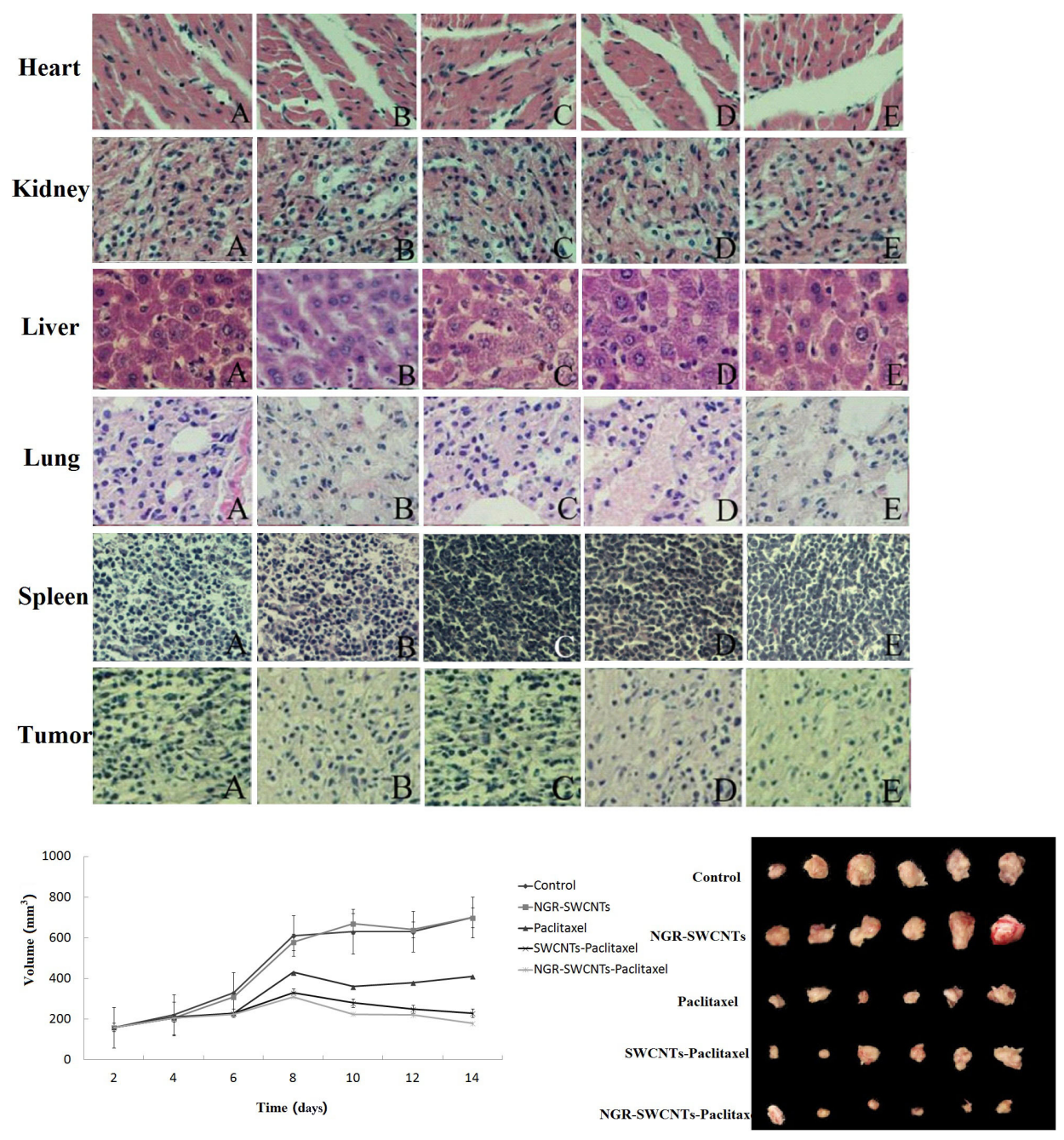

Figure 7. HE dyed results and the tumor volume in mouse models.

\section{CONCLUSION}

The NGR-SWCNT-Paclitaxel complex was systematically investigated in the present study from the preparation of the complex and lyophilized powder to its in vitro and in vivo biological activity. The precipitation method was shown to be suitable for preparing the SWCNT-Paclitaxel complex. The optimal prescription of the NGR-SWCNT-Paclitaxel complex lyophilized powder was determined. Cell absorption experiments demonstrated that the NGR-SWCNT-Paclitaxel complex could effectively be transferred to MCF-7 cells and inhibit the proliferation of breast cancer cells. The inhibition occurred in a concentration- and time-dependent manner. The paclitaxel concentrations in Sprague-Dawley rats' plasma and in the tissues of tumor-bearing mice were inspected by HPLC. The pharmacodynamic analysis 
demonstrated that the NGR-SWCNT-Paclitaxel complex had a sustained-release effect. The NGR-SWCNT-Paclitaxel complex increased the paclitaxel concentration in the liver, lung, spleen, kidney, and tumor tissue, and showed obvious targeting to the liver and tumors. The complex also elicited a great change in the paclitaxel distribution in vivo. Compared with the control group, the NSP group had distinctly smaller tumors, which indicated that the NGRSWCNT-Paclitaxel complex had a better therapeutic effect.

\section{REFERENCES}

Adolph MA, Xavier YM, Kriveshini P and Rui K (2012). Phosphine functionalised multiwalled carbon nanotubes: a new adsorbent for the removal of nickel from aqueous solution. J. Environ. Sci. 24: 1133-1141.

Andersen AJ, Robinson JT, Dai H, Hunter AC, et al. (2013). Single-walled carbon nanotube surface control of complement recognition and activation. ACS Nano 7: 1108-1119.

Bearden S and Zhang G (2013). The effects of the electrical double layer on giant ionic currents through single-walled carbon nanotubes. Nanotechnology 24: 125204.

Duque JG, Oudjedi L, Crochet JJ, Tretiak S, et al. (2013). Mechanism of electrolyte-induced brightening in single-wall carbon nanotubes. J. Am. Chem. Soc. 135: 3379-3382.

Gao W, Xiang B, Meng TT, Liu F, et al. (2013). Chemotherapeutic drug delivery to cancer cells using a combination of folate targeting and tumor microenvironment-sensitive polypeptides. Biomaterials 34: 4137-4149.

Germano G, Frapolli R, Belgiovine C, Anselmo A, et al. (2013). Role of macrophage targeting in the antitumor activity of trabectedin. Cancer Cell 23: 249-262.

Kam NW, Liu Z and Dai H (2006). Carbon nanotubes as intracellular transporters for proteins and DNA: an investigation of the uptake mechanism and pathway. Angew. Chem. Int. Ed. Engl. 45: 577-581.

Luan Y, Jing F, Zhang J, Zou M, et al. (2012). Design, synthesis, and activity evaluation of a new 5-fluorouracil prodrug containing an Asn-Gly-Arg(NO2)COOCH3 tripeptide. Protein Pept. Lett. 19: 1122-1131.

Luo LM, Huang Y, Zhao BX, Zhao X, et al. (2013). Anti-tumor and anti-angiogenic effect of metronomic cyclic NGRmodified liposomes containing paclitaxel. Biomaterials 34: 1102-1114.

Maehana T, Mizuno T, Muto M, Nishiyama N, et al. (2010). Scleroderma-like skin sclerosis induced by docetaxel chemotherapy for hormone refractory prostate cancer: a case report. Nihon Hinyokika Gakkai Zasshi 101: 726-729.

Majumder M, Stinchcomb A and Hinds BJ (2010). Towards mimicking natural protein channels with aligned carbon nanotube membranes for active drug delivery. Life Sci. 86: 563-568.

Matthews IP, Gregory CJ, Aljayyoussi G, Morris CJ, et al. (2013). Maximal extent of translocation of single-walled carbon nanotubes from lung airways of the rat. Environ. Toxicol. Pharmacol. 35: 461-464.

Ohta R, Gunjishima I, Shinozaki K, Hatanaka T, et al. (2010). Anti-agglomerating effect in vertically aligned carbon nanotubes derived by antisolvent precipitation of naphthalene. Chem. Commun. 46: 5259-5261.

Shahin M, Soudy R, Aliabadi HM, Kneteman N, et al. (2013). Engineered breast tumor targeting peptide ligand modified liposomal doxorubicin and the effect of peptide density on anticancer activity. Biomaterials 34: 4089-4097.

Shanthi M, Mathew CM, Ulaganathan M and Rajendran S (2013). FT-IR and DSC studies of poly(vinylidene chloride-coacrylonitrile) complexed with LiBF4. Spectrochim. Acta A. Mol. Biomol. Spectrosc. 109: 105-109.

Sinnott SB (2002). Chemical functionalization of carbon nanotubes. J. Nanosci. Nanotechnol. 2: 113-123.

Sundararajan M and Ghosh SK (2011). Designing novel materials through functionalization of carbon nanotubes for application in nuclear waste management: speciation of uranyl. J. Phys. Chem. A. 115: 6732-6737.

Xiao Y, Gao X, Taratula O, Treado S, et al. (2009). Anti-HER2 IgY antibody-functionalized single-walled carbon nanotubes for detection and selective destruction of breast cancer cells. BMC Cancer 9: 351.

Zucali PA, Simonelli M, De Vincenzo F, Lorenzi E, et al. (2013). Phase I and pharmacodynamic study of high-dose NGRhTNF in patients with refractory solid tumours. Br. J. Cancer 108: 58-63. 